\title{
Ready meals and nutrient standards: challenges and opportunities
}

\author{
A. Anderson, W. Wrieden, S. Tasker and A. Gregor \\ University of Dundee, Dundee, UK
}

There is increasing 'recognition that policies directed at food and diet need to recognise the significance of food bought for the home in supermarkets' including ready meals, which have increased in consumption threefold since $1997^{(1)}$.

Current benchmarks for nutrient standards of meals include the Caroline Walker Trust guidelines for meals ${ }^{(2)}$ and the Food Standards Agency traffic lights (low, medium and high levels for salt, fat, sugar and saturates) ${ }^{(3)}$. Using the standard energy requirement of $8372 \mathrm{~kJ}$ $(2000 \mathrm{kcal}) / \mathrm{d}$ in combination with these standards it is now possible to identify a benchmark for a balanced meal that is low in fat, saturated fats, salt and sugar. The aim of the current work was to identify the proportion of widely-available ready meals that meet these benchmarks.

Data were sought by writing to sixty companies, undertaking web searches for compositional information and from nutrient information presented on the packages of ready meals. All five major retail food stores as well as department stores and smaller stores were visited. Any meals branded as 'healthy' were categorised for separate analysis. Data on macronutrient composition per $100 \mathrm{~g}$ and per serving were recorded. Additional nutrient information (e.g. micronutrients) was not collected because these data were not reported on the label in a systematic manner.

Seven of the companies contacted replied and two supplied relevant information. Searching websites and purchasing additional products resulted in data from a total of 300 meals (one-course savoury items). These products were retailed as twenty brands, the majority of which (228) were in a chilled format and the remainder (seventy-two) were frozen; 203 (68\%) were marketed as part of a 'healthy range'. Of the 300 meals, none complied with the Caroline Walker Trust standards, largely because of the low energy values. However, if energy values were excluded sixty-two of 300 meals $(21 \%)$ complied. Of the sixty-two meals, fifty-five were specifically marketed and labelled as being part of a 'healthy' range of ready meals. Thus, $7 \%$ of non-health-marketed meals and $27 \%$ labelled healthy met the criterion.

\begin{tabular}{|c|c|c|c|}
\hline Nutrient & $\begin{array}{l}\text { Min-max range for all } \\
\text { meals }(n \text { 300) }\end{array}$ & $\begin{array}{l}\text { Min-max range for } \\
\text { meals marketed } \\
\text { as 'healthy' }(n \text { 203) }\end{array}$ & $\begin{array}{c}\text { Caroline Walker Trust } \\
\text { nutrient-meal } \\
\text { based standards }\end{array}$ \\
\hline Energy: kJ & $871-4194$ & $871-2427$ & 2512 \\
\hline kcal & $208-1002$ & $208-580$ & 600 \\
\hline$(\% 8372 \mathrm{~kJ}(2000 \mathrm{kcal}))$ & $10.4-50.1$ & $10.4-29.0$ & $30 \%$ daily energy \\
\hline Fat $(\% 8372 \mathrm{~kJ}(2000 \mathrm{kcal}))$ & $1.3-58.5$ & $1.3-47.1$ & $\leq 35$ \\
\hline Saturated fat $(\% 8372 \mathrm{~kJ}(2000 \mathrm{kcal}))$ & $0.9-36.0$ & $0.9-29.1$ & $\leq 11$ \\
\hline Sugars $(\% 8372 \mathrm{~kJ}(2000 \mathrm{kcal}))$ & $0.3-34.6$ & $0.7-34.6$ & $\leq 11 \%$ NMES \\
\hline Protein: $\mathrm{g}$ & $8.4-58.3$ & $8.4-55.1$ & $\geq 13.5$ \\
\hline$\%$ RNI & $18.7-130$ & $18.7-122$ & 30 \\
\hline Sodium: mg & $80-2200$ & $80-1200$ & $\leq 710$ \\
\hline$\%$ SACN maximum & $3.3-91.6$ & $3.3-50$ & $\begin{array}{l}\text { Equivalent to } 30 \% \\
\text { SACN } 6 \mathrm{~g} \mathrm{salt} / \mathrm{d}^{(4)}\end{array}$ \\
\hline
\end{tabular}

It was recognised that some meals would comply with the standards with the exception of a single nutrient (apart from energy). Four meals fell within the guidelines with the exception of fat; twenty-eight with the exception of sugar; thirty-one with the exception of saturated fat and forty-three with the exception of salt.

In conclusion these results indicate that there is scope for manufacturers to make relatively small adjustments to meet current standards. However, meeting energy requirements remains a major challenge.

This project was supported by The Circulation Foundation.

1. The Cabinet Office (2008) Food: an analysis of issues. http://www.cabinetoffice.gov.uk/strategy/work_areas/food_policy.aspx

2. Crawley H (2005) Eating Well at School: Nutritional and Practical Guidelines. Abbots Langley Herts.: Caroline Walker Trust.

3. Food Standards Agency (2007) Front-of-pack traffic light signpost labelling technical guidance: Issue 2. http://www.food.gov.uk/multimedia/pdfs/ frontofpackguidance2.pdf

4. Scientific Advisory Committee on Nutrition (2003) Salt and health. http://www.sacn.gov.uk/pdfs/sacn_salt_final.pdf 